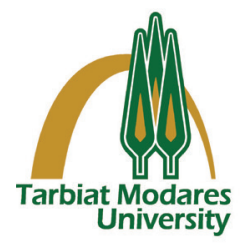

\title{
Characteristics of Methicillin Resistant Staphylococcus aureus Strains Isolated from Hospital Wastewater in Tehran, Iran
}

\section{ART ICLE INF O}

Article Type

Original Research

Authors

Mina Torabi, $M S c^{1}$

Fateh Rahimi, $P h D^{2 *}$

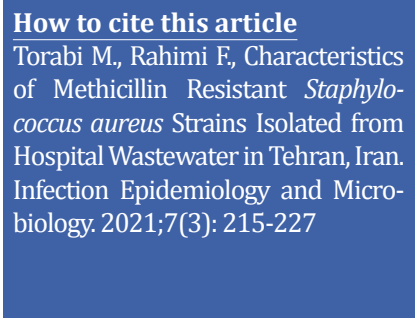

${ }^{1}$ Department of Microbiology, Faculty of Biological Science and Technology, University of Isfahan, Isfahan, Iran

${ }^{2}$ Department of Microbiology, Faculty of Biological Science and Technology, University of Isfahan, Hezar-Jareeb Street, Isfahan, Iran

\section{* Correspondence}

Address: Department of Microbiology, Faculty of Biological Science and Technology, University of Isfahan, HezarJerib st, Isfahan, Iran. f.rahimi@sci.ui.ac.ir

\section{A B S T R A C T}

Backgrounds: Hospital sewage is known as an important source of human pathogenic bacteria such as methicillin resistant Staphylococcus aureus (MRSA) strains disseminated from hospital to the environment. This study aimed to investigate the presence of MRSA in the treated outgoing wastewater collected from a referral hospital in Tehran, Iran.

Materials \& Methods: During 2015, sampling was carried out at two stages from a hospital wastewater. All black colonies with halos on HiCrome aureus agar medium supplemented with oxacillin were collected and identified as MRSA using specific primers for nucA and mecA genes. Isolates susceptibility to 18 antibiotics was determined according to the recommendations of the Clinical and Laboratory Standards Institute (CLSI). Bacterial typing was performed for the isolates using a combination of Phene plate ( $\mathrm{PhP}$ ) typing, prophage typing, staphylococcal cassette chromosome mec (SCCmec) and ccr typing methods.

Findings: A total of 79 MRSA isolates were confirmed using specific primers and showed susceptibility to quinupristin-dalfopristin, vancomycin, chloramphenicol, and linezolid. High resistance to penicillin, ciprofloxacin, kanamycin, tobramycin, and erythromycin was reported. Sixteen PhP types consisting of eight common types (CTs) and eight single types (STs) were identified among the strains, among which CT1 was the dominant type. Also, two prophage patterns and four prophage types were identified, and all the strains were positive for SCCmec type III and ccr type 3.

Conclusion: The results of this study revealed that sewage-treatment process was able to remove community-acquired MRSA (CA-MRSA) strains; however, hospital-acquired MRSA (HA-MRSA) strains were able to survive during the treatment process in this hospital.

Keywords: Methicillin resistant Staphylococcus aureus, Wastewater, Hospital, Bacterial typing, Community-acquired MRSA, Hospital-acquired MRSA.

\section{CITATION LINKS}

[1] Hanssen AM, Ericson Sollid JU. SCCmec in ... [2] Rahimi F, Katouli M, Karimi S. Biofilm ... [3] Rahimi F, Katouli M, Pourshafie MR. Characteristics of ... [4] Fatholahzadeh B, Emaneini M, Gilbert G, Udo E, Aligholi M, Modarressi MH, et al. Staphylococcal ... [5] Rahimi F, Katouli M, Pourshafie MR. Characterization of ... [6] Börjesson S, Dienues O, Jarnheimer P-Å, Olsen B, Matussek A, Lindgren P-E. Quantification of genes ... [7] Börjesson S, Matussek A, Melin S, Löfgren S, Lindgren P-E. Methicillin-resistant ... [8] Börjesson S, Melin S, Matussek A, Lindgren P-E. A seasonal study of the mecA gene and ... [9] Goldstein RER, Micallef SA, Gibbs SG, Davis JA, He X, George A, et al. Methicillin-resistant ... [10] Rahimi F, Bouzari M. Biochemical fingerprinting of methicillin-resistant ... [11] Thompson J, Gündoğdu A, Stratton H, Katouli M. Antibiotic ... [12] Rahimi F, Shokoohizadeh L. Characterization of ... [13] Pantůček R, Doškař J, Růžičková V, Kašpárek P, Oráčová E, Kvardová V, et al. Identification ... [14] Rahimi F, Bouzari M, Katouli M, Pourshafie MR. Prophage and ... [15] Clinical and Laboratory Standard Institute C. Performance standards ... [16] Zhang K, McClure J-A, Elsayed S, Louie T, Conly JM. Novel multiplex ... [17] Rahimi F, Karimi S. Characteristics of methicillin resistant ... [18] Rahimi F, Karimi S. Isolation of methicillin-resistant ... [19] Rahimi F, Qasemi A. Epidemiological link between ... [20] Rahimi F, Shafiei R. Characteristics of enterotoxin-producing ... [21] Rahimi F, Shokoohizadeh L. Characterization of virulence factors and ... [22] Schwartz T, Kohnen W, Jansen B, Obst U. Detection of antibiotic-resistant ... [23] Goudarzi M, Goudarzi H, Figueiredo AMS, Udo EE, Fazeli M, Asadzadeh M, et al. Molecular ... [24] Rahimi F, Bouzari M, Katouli M, Pourshafie MR. Antibiotic resistance pattern of ... [25] Rahimi F, Bouzari M, Maleki Z, Rahimi F. Antibiotic susceptibility pattern ... [26] Rahimi F, Bouzari M, Katouli M, Pourshafie M. Prophage typing of ... [27] Rahimi F, Karimi S. Characteristics of virulence factors in ...

\section{Article History}

Received: May 052021

Accepted: June 25,2021

Published: July 20,2021 


\section{Introduction}

Staphylococcus aureus is known as one of the most common human bacterial pathogen and the cause of a variety of infections such as skin and soft tissue infections, septicemia, fatal necrotizing pneumonia, osteomyelitis, endovascular infections, endocarditis, septic arthritis, and food poisoning [1]. The high potential of $S$. aureus to cause a broad spectrum of important infections in humans is due to the expression of a variety of virulence factors that participate in pathogenesis and allow this bacterium to adhere to surface/tissues, evade from the immune system, and produce different enzymes and lethal toxins ${ }^{[2]}$. S. aureus strains have the ability to acquire mobile genetic elements and show resistance to a variety of antimicrobial agents and different classes of antibiotics.

Methicillin was first introduced in 1960 to treat infections caused by penicillin resistant $S$. aureus strains, and the first methicillin resistant $S$. aureus (MRSA) strain was reported in 1961 in the United Kingdom. Over the past decades, different clonal groups of $S$. aureus have disseminated in different communities and hospitals worldwide ${ }^{[3]}$. Resistance to methicillin could be due to the presence of mecA gene encoding a penicillin binding protein $2 \mathrm{a}$ (PBP2a) which has a low affinity for most semi-synthetic penicillins, such as methicillin, oxacillin, and nafcillin ${ }^{[4]}$. The mecA gene and its regulatory genes (e.g. $m e c \mathrm{I}$ and $m e c \mathrm{R}$ ) are part of a mobile genetic element called staphylococcal cassette chromosome mec (SCCmec). Based on the mec gene complex classes and the cassette chromosome recombinase ( $c c r$ ) gene types, 13 different types of SCCmec have been reported so far among livestock-associated MRSA (LA-MRSA), hospital-acquired MRSA (HA-MRSA), and community-acquired MRSA (CA-MRSA) ${ }^{[5]}$.

Sewage is one of the most important sources for persistence and dissemination of different pathogenic bacteria as well as antibiotic resistance genes in the environment and community. Also, S. aureus is released to the environment directly or via the urban and hospital sewage and could persist there for a long time. Hospital sewage plays an important role in the dissemination of clonal groups of MRSA strains from the hospital environment to the community. The presence of MRSA strains in hospital sewage and sewage-treatment plants (STPs) has already been reported in Iran and other countries [5-11]. Therefore, typing of MRSA strains could be a useful method to reveal their clonal dissemination in different geographical regions. Different typing methods such as SCCmec typing, prophage typing, pulsed field gel electrophoresis (PFGE), multilocus sequence typing (MLST), spa typing, coa typing, and Phene Plate (PhP) biochemical fingerprinting are commonly used in epidemiological studies on MRSA ${ }^{[12]}$. PhP biochemical fingerprinting is a highresolution powerful method used to type different pathogenic bacteria such as MRSA. This system is based on the measurement of the absorbance value of fermentation reactions at three different intervals, and data are analyzed using PhPWin software (PhPlate Microplates Techniques AB, Sweden) [3, 11]. To date, more than 250 staphylococcal bacteriophages have been identified and classified into SGA, SGB, SGD, SGF (SGFa and SGFb), and SGL prophage types according to their morphology as well as lytic and serological activities. Prophage typing is one of the most common typing method used extensively for different bacterial genera and species. This method is a time-consuming and tedious method needing to an international phage set that is not available in most laboratories. On the other hand, detection of different prophage genes among MRSA strains using specific 
primers is a convenient, reliable, and rapid method that could be employed to detect different prophage types among MRSA strains ${ }^{[13-14] .}$

Objectives: The present study aimed to investigate the presence of different clonal groups of multidrug resistant MRSA strains in the wastewater of a referral hospital in Tehran, Iran.

\section{Materials and Methods}

Sampling and isolation of strains: During February to March 2015, two sewage samples were collected from the treated outgoing wastewater of a referral hospital in Tehran, Iran. Samples were collected in sterile (500 $\mathrm{mL})$ bottles and transferred to the laboratory while maintaining cold chain. All samples were five-fold diluted using phosphate buffered saline (PBS). Then 500 $\mathrm{mL}$ of each diluted sample was filtered through a $0.45 \mu \mathrm{m}$ membrane (Millipore Corporation, Burlington, MA, USA) and placed on HiCrome aureus agar medium (Hi Media Ltd, Mumbai, India) supplemented with $1 \mu \mathrm{g} / \mathrm{mL}$ of oxacillin antibiotic (SigmaAldrich, Mo, USA) and incubated at $37^{\circ} \mathrm{C}$ for 48 hrs ${ }^{[10]}$. Black colonies with opaque halos were selected and identified as MRSA using specific primers for nucA and mecA genes as described previously ${ }^{[3]}$.

Antibiotic susceptibility testing: All oxacillin resistant $S$, aureus strains were examined for susceptibility to amikacin $(30 \mu \mathrm{g})$, cefoxitin $(30 \mu \mathrm{g})$, ciprofloxacin (5 $\mu \mathrm{g})$, chloramphenicol $(30 \mu \mathrm{g})$, clindamycin $(2 \mu \mathrm{g})$, erythromycin $(15 \mu \mathrm{g})$, gentamicin $(10 \mu \mathrm{g})$, kanamycin $(30 \mu \mathrm{g})$, linezolid (30 $\mu \mathrm{g})$, minocycline $(30 \mu \mathrm{g})$, nitrofurantoin (50 $\mathrm{gg})$, penicillin (10 U), quinupristindalfopristin $(15 \mu \mathrm{g})$, rifampin $(5 \mu \mathrm{g})$, tetracycline (30 $\mu \mathrm{g})$, trimethoprimsulfamethoxazole (1.25-23.75 $\mu \mathrm{g})$, and tobramycin (10 $\mu \mathrm{g})$ (Rosco, Denmark) using disc diffusion method according to the recommendations of the Clinical and Laboratory Standards Institute, 2016 (CLSI, 2016) [15]. The minimum inhibitory concentration (MIC) of oxacillin and vancomycin (Sigma-Aldrich, Germany) against MRSA strains was determined using broth microdilution method according to the guidelines of CLSI (2016) ${ }^{[15]}$. MRSA and vancomycin resistant $S$. aureus (VRSA) strains were resistant to $\geq 4$ and $\geq 16 \mu \mathrm{g} / \mathrm{mL}$ of oxacillin and vancomycin, respectively.

DNA extraction: DNA of MRSA strains was extracted using a DNA extraction kit from Gene Transfer Pioneers Company according to the instructions of the manufacturer.

Identification of MRSA strains: All suspected colonies were identified as $S$. aureus strains using specific primers for nucA gene (Table 1) encoding thermonuclease enzyme as described previously [3]. Moreover, to confirm MRSA strains, the presence of mecA gene was tested by specific primers ${ }^{[3]}$.

\section{Typing of MRSA strains:}

Prophage typing. Specific primers (Table 1) and multiplex-PCR reaction were employed to detect SGA, SGB, SGF, SGFa, SGFb, SGD, and SGL prophage types among MRSA strains according to the previously described instructions ${ }^{[13]}$.

SCCmec and ccr typing. The presence of different SCCmec types among MRSA strains was tested using multiplex-PCR assay by employing specific primers (types I-V) (Table 1) according to the protocol previously described by Zhang et al. (2005) ${ }^{[16]}$. Also, another multiplex-PCR assay was employed for ccr typing of MRSA strains as published previously ${ }^{[16]}$.

PhP typing. The high-resolution PhenePlate system (PhPlate AB, Stockholm, Sweden) was employed for prophage typing of MRSA strains according to the guidelines of manufacturer and the protocol described previously ${ }^{[3,12]}$. 
Table 1) Primers used in this study.

\begin{tabular}{|c|c|c|c|}
\hline Primer & Sequence $\left(5^{\prime}\right.$ to $\left.3^{\prime}\right)$ & Size (bp) & Reference \\
\hline nисA-F & TAATGTACAAAGGTCAAC & \multirow{2}{*}{310} & \multirow{2}{*}{3} \\
\hline$n u c A-R$ & TGATAAATATGGACGTGGCT & & \\
\hline mecA-F & TGGCTATCGTGTCACAATCG & \multirow{2}{*}{195} & \multirow{2}{*}{3} \\
\hline mecA-R & CTGGAACTTGTTGAGCAGAG & & \\
\hline SCCmec type I-F & GCTTTAAAGAGTGTCGTTACAGG & \multirow{2}{*}{613} & \multirow{2}{*}{16} \\
\hline SCCmec type I-R & GTCTCTCATAGTATGACGTCC & & \\
\hline SCCmec type II-F & CGTTGAAGATGATGAAGCG & \multirow{2}{*}{398} & \multirow{2}{*}{16} \\
\hline SCCmec type II-R & CGAAATCAATGGTTAATGGACC & & \\
\hline SCCmec type III-F & CCATATTGTGTACGATGCG & \multirow{2}{*}{280} & \multirow{2}{*}{16} \\
\hline SCCmec type III-R & CCTTAGTTGTCGTAACAGATCG & & \\
\hline SCCmec type IVa-F & GCCTTATTCGAAGAAACCG & \multirow{2}{*}{776} & \multirow[b]{2}{*}{16} \\
\hline SCCmec type IVa-R & СТАСТСTTCTGAAAAGCGTCG & & \\
\hline SCCmec type IVb-F & TCTGGAATTACTTCAGCTGC & \multirow{2}{*}{493} & \multirow{2}{*}{16} \\
\hline SCCmec type IVb-R & АААСААТАТTGСТСТСССТС & & \\
\hline SCCmec type IVc-F & ACATATTTGTATTATCGGAGAGC & \multirow{2}{*}{200} & \multirow{2}{*}{16} \\
\hline SCCmec type IVc-R & TTGGTATGAGGTATTGCTGG & & \\
\hline SCCmec type IVd-F & СТСАAАATACGGACCCCAATACA & \multirow{2}{*}{881} & \multirow{2}{*}{16} \\
\hline SCCmec type IVd-R & TGCTCCAGTAATTGCTAAAG & & \\
\hline SCCmec type V-F & GAACATTGTTACTTAAATGAGCG & \multirow{2}{*}{325} & \multirow{2}{*}{16} \\
\hline SCCmec type V-R & TGAAAGTTGTACCCTTGACACC & & \\
\hline SGA-F & TATCAGGCGAGAATTAAGGG & \multirow{2}{*}{744} & \multirow{2}{*}{13} \\
\hline SGA-R & CTTTGACATGACATCCGCTTGAC & & \\
\hline SGB-F & ACTTATCCAGGTGGYGTTATTG & \multirow{2}{*}{405} & \multirow{2}{*}{13} \\
\hline SGB-R & TGTATTTAATTTCGCCGTTAGTG & & \\
\hline SGF-F & CGATGGACGGCTACACAGA & \multirow{2}{*}{155} & \multirow{2}{*}{13} \\
\hline SGF-R & TTGTTCAGAAACTTCCСAACCTG & & \\
\hline SGFa-F & TACGGGAAAATATTCGGAAG & \multirow{2}{*}{548} & \multirow{2}{*}{13} \\
\hline SGFa-R & ATAATCCGCACCTCATTCCT & & \\
\hline $\mathrm{SGFb}-\mathrm{F}$ & AGACACATTAAGTCGCACGATAG & \multirow{2}{*}{147} & \multirow{2}{*}{13} \\
\hline $\mathrm{SGFb}-\mathrm{R}$ & TCTTCTCTGGCACGGTCTCTT & & \\
\hline SGD-F & TGGGCTTCATTCTACGGTGA & & \\
\hline SGD-R & GTAATTTAATGAATCCACGAGAT & 331 & 13 \\
\hline SGL-F & GCTTAAAACAGTAACGGTGACAGTG & & \\
\hline SGL-R & TGCTACATCATCAAGAACACCTGG & 748 & 13 \\
\hline
\end{tabular}


Table 2) Antibiotic resistance patterns among MRSA strains

\begin{tabular}{|c|c|c|c|}
\hline Antibiotics & Pattern & No & $\%$ \\
\hline One antibiotic & & 6 & 8 \\
\hline $\mathrm{P}$ & 1 & 6 & 8 \\
\hline Three antibiotics & & 3 & 4 \\
\hline P, CIP, TS & 2 & 1 & 1 \\
\hline P, CIP, RP & 3 & 2 & 3 \\
\hline Four antibiotics & & 2 & 3 \\
\hline $\mathrm{P}, \mathrm{CIP}, \mathrm{E}, \mathrm{T}$ & 4 & 2 & 3 \\
\hline Five antibiotics & & 8 & 10 \\
\hline $\mathrm{P}, \mathrm{CIP}, \mathrm{K}, \mathrm{TN}, \mathrm{RP}$ & 5 & 3 & 4 \\
\hline $\mathrm{P}, \mathrm{CIP}, \mathrm{K}, \mathrm{AN}, \mathrm{TN}$ & 6 & 5 & 6 \\
\hline Six antibiotics & & 1 & 1 \\
\hline $\mathrm{P}, \mathrm{CIP}, \mathrm{K}, \mathrm{AN}, \mathrm{TN}, \mathrm{RP}$ & 7 & 1 & 1 \\
\hline Seven antibiotics & & 4 & 5 \\
\hline $\mathrm{P}, \mathrm{CIP}, \mathrm{E}, \mathrm{K}, \mathrm{AN}, \mathrm{TN}, \mathrm{CD}$ & 8 & 4 & 5 \\
\hline Eight antibiotics & & 1 & 1 \\
\hline P, CIP, E, K, AN, TN, CD, TS & 9 & 1 & 1 \\
\hline Nine antibiotics & & 9 & 11 \\
\hline $\mathrm{P}, \mathrm{CIP}, \mathrm{E}, \mathrm{K}, \mathrm{AN}, \mathrm{TN}, \mathrm{CD}, \mathrm{T}, \mathrm{RP}$ & 10 & 7 & 9 \\
\hline P, CIP, E, K, AN, TN, CD, RP, GM & 11 & 2 & 3 \\
\hline Ten antibiotics & & 17 & 22 \\
\hline P, CIP, E, K, TN, T, CD, TS, RP, MN & 12 & 3 & 4 \\
\hline P, CIP, E, K, AN, TN, T, CD, RP, MN & 13 & 6 & 8 \\
\hline $\mathrm{P}, \mathrm{CIP}, \mathrm{E}, \mathrm{K}, \mathrm{AN}, \mathrm{TN}, \mathrm{T}, \mathrm{CD}, \mathrm{TS}, \mathrm{MN}$ & 14 & 1 & 1 \\
\hline P, CIP, E, K, AN, TN, T, CD, TS, RP & 15 & 1 & 1 \\
\hline P, CIP, E, K, AN, TN, T, CD, TS, GM & 16 & 2 & 3 \\
\hline P, CIP, E, K, AN, TN, CD, TS, RP, GM & 17 & 2 & 3 \\
\hline P, CIP, E, K, AN, TN, T, TS, MN, GM & 18 & 2 & 3 \\
\hline Eleven antibiotics & & 25 & 32 \\
\hline P, CIP, E, K, AN, TN, T, CD, TS, MN, GM & 19 & 11 & 14 \\
\hline P, CIP, E, K, AN, TN, T, CD, TS, RP, GM & 20 & 6 & 8 \\
\hline P, CIP, E, K, AN, TN, T, CD, RP, MN, GM & 21 & 3 & 4 \\
\hline P, CIP, E, K, AN, TN, T, CD, TS, RP, MN & 22 & 3 & 4 \\
\hline P, CIP, E, K, AN, TN, T, CD, TS, RP, NI & 23 & 1 & 1 \\
\hline P, CIP, E, K, AN, TN, T, CD, RP, MN, NI & 24 & 1 & 1 \\
\hline Twelve antibiotics & & 3 & 4 \\
\hline P, CIP, E, K, AN, TN, T, CD, TS, RP, GM, MN & 25 & 3 & 4 \\
\hline
\end{tabular}

P: penicillin, CIP: ciprofloxacin, K: kanamycin, TN: tobramycin, E: erythromycin, AN: amikacin, CD: clindamycin, T: tetracycline, RP: rifampin, TS: sulfamethoxazole-trimethoprim, MN: minocycline, GM: gentamicin, NI: nitrofurantoin. 


\section{Findings}

Isolation and identification of strains: A total of 79 black colonies, surrounded by halos and suspected to MRSA, were isolated from HiCrome aureus agar plates supplemented with oxacillin. All the isolates were positive for nucA gene and harbored mecA gene and identified as MRSA. Of 79 MRSA strains, 37 (47\%) strains were isolated in the first sampling stage in February, and 42 $(53 \%)$ isolates were isolated in the second sampling stage in March.

Antibiotic susceptibility testing: All mecA positive strains showed resistance to cefoxitin and penicillin. Moreover, all 79 MRSA strains were susceptible to quinupristin-dalfopristin, vancomycin, chloramphenicol, and linezolid. The highest resistance (78-92\%) was observed to ciprofloxacin, kanamycin, tobramycin, erythromycin, amikacin, tetracycline, and clindamycin (Figure 1). On the other hand, the rate of resistance to rifampin, trimethoprimsulfamethoxazole, minocycline, gentamicin, and nitrofurantoin was also 3-62\%.

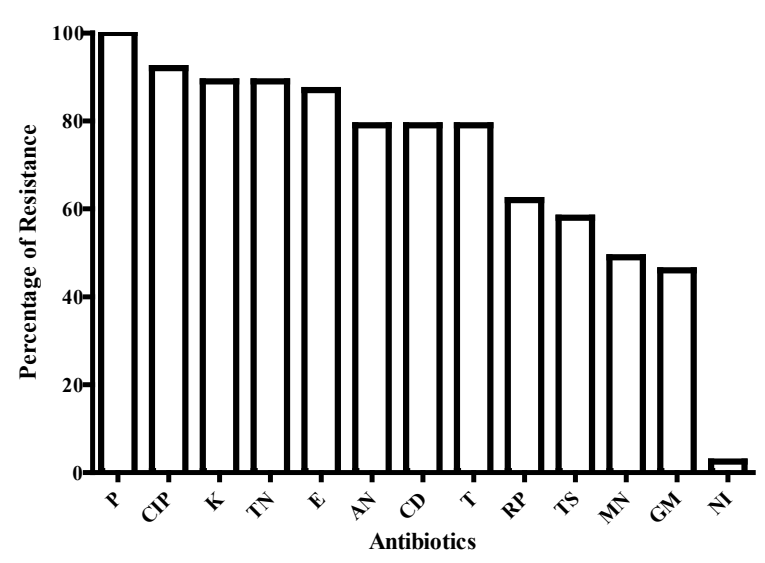

Figure 1) Resistance to antibiotics among MRSA strains isolated from hospital sewage P: penicillin, CIP: ciprofloxacin, K: kanamycin, TN: tobramycin, E: erythromycin, AN: amikacin, CD: clindamycin, T: tetracycline, RP: rifampin, TS: sulfamethoxazole-trimethoprim, MN: minocycline, GM: gentamicin, NI: nitrofurantoin.

According to the results of the antibiotic susceptibility testing, 25 resistance patterns were identified among MRSA strains, and strains showed resistance to 1-12 antibiotics, of which 6 strains were only resistant to penicillin (Table 2). Moreover, most of the MRSA strains $(n=25,32 \%)$ were resistant to 11 antibiotics. On the other hand, 17 (22\%) and $3(4 \%)$ strains showed resistance to 10 and 12 antibiotics, respectively. Totally, 92\% of MRSA strains were classified as multidrug resistant (MDR) strains and showed resistance to at least one antimicrobial agent in three or more antibiotic categories. The results of MIC of oxacillin revealed that $38 \%(n=30)$ and $30 \%(n=24)$ of MRSA strains were resistant to 2048 and 1024 $\mu \mathrm{g} / \mathrm{mL}$ of oxacillin (Figure 2), respectively. Furthermore, 6 MRSA strains (8\%) which were only resistant to penicillin showed resistance to $32 \mu \mathrm{g} / \mathrm{mL}$ of oxacillin. Moreover, MIC of vancomycin for all MRSA strains was $\leq 1 \mu \mathrm{g} / \mathrm{mL}$, and 24 (30\%), 37 (47\%), and 8 (10\%) strains showed resistance to $1,0.25$, and $0.5 \mu \mathrm{g} / \mathrm{mL}$ of vancomycin, respectively.

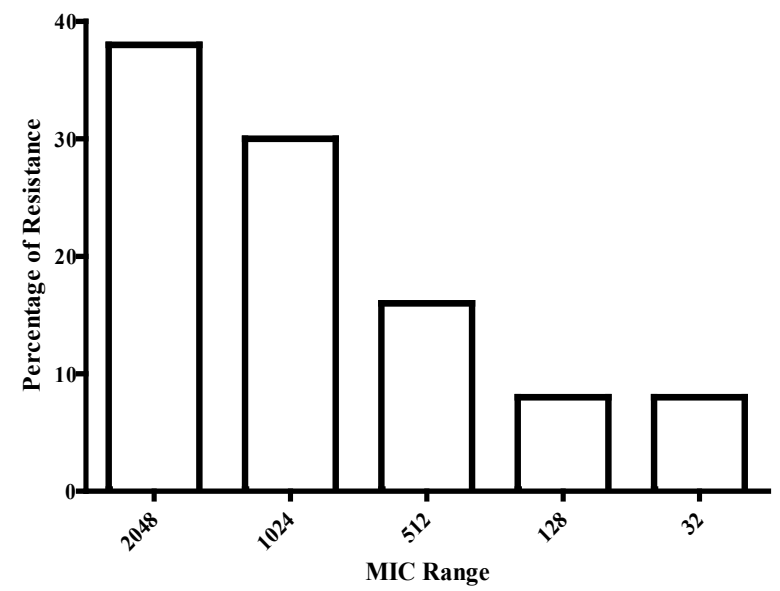

Figure 2) The range of oxacillin MICs among MRSA strains: MRSA had MIC $\geq 4 \mu \mathrm{g} / \mathrm{mL}$

Prophage typing: The results of prophage typing of MRSA strains showed that none of the strains were positive for SGA, SGD, and SGL prophage types, and the prevalence of prophage types was only limited to SGB, SGF, and two SGF subtypes (SGFa and SGFb). SGF prophage type and its two subtypes were 
Table 3) Frequency of different prophage patterns among MRSA isolates

\begin{tabular}{crrrrrrrr}
\hline \multirow{8}{*}{$\begin{array}{l}\text { Prophage } \\
\text { Pattern }\end{array}$} & \multicolumn{9}{c}{ Prophage Types } & \multirow{2}{*}{ Frequency } \\
\cline { 2 - 7 } & SGA & SGB & SGF & SGFa & SGFb & SGD & SGL & \\
\hline 1 & - & + & + & + & + & - & - & $57(72 \%)$ \\
\hline 2 & - & - & + & + & + & - & - & $22(82 \%)$ \\
\hline
\end{tabular}

Table 4) Clonality of MRSA strains isolated from hospital sewage in Tehran during 2015

\begin{tabular}{|c|c|c|c|c|c|c|}
\hline PhP Types & No & $\begin{array}{l}\text { Month of } \\
\text { Sampling } \\
\end{array}$ & Prophage Pattern & SCCmec Type & $\begin{array}{l}\text { ccr } \\
\text { Type }\end{array}$ & MIC $(\mu \mathrm{g} / \mathrm{mL})$ \\
\hline \multirow{29}{*}{ CT1 } & 1 & February & 1 & III & 3 & 64 \\
\hline & 2 & February & 1 & III & 3 & 64 \\
\hline & 3 & February & 1 & III & 3 & 64 \\
\hline & 4 & February & 1 & III & 3 & 512 \\
\hline & 5 & March & 2 & III & 3 & 1024 \\
\hline & 6 & March & 2 & III & 3 & 256 \\
\hline & 7 & March & 2 & III & 3 & 256 \\
\hline & 8 & February & 1 & III & 3 & 1024 \\
\hline & 9 & February & 2 & III & 3 & 1024 \\
\hline & 10 & February & 2 & III & 3 & 2048 \\
\hline & 11 & February & 2 & III & 3 & 2048 \\
\hline & 12 & February & 2 & III & 3 & 1024 \\
\hline & 13 & March & 2 & III & 3 & 2048 \\
\hline & 14 & March & 2 & III & 3 & 512 \\
\hline & 15 & February & 2 & III & 3 & 512 \\
\hline & 16 & March & 1 & III & 3 & 512 \\
\hline & 17 & February & 1 & III & 3 & 512 \\
\hline & 18 & February & 1 & III & 3 & 2048 \\
\hline & 19 & February & 2 & III & 3 & 1024 \\
\hline & 20 & March & 1 & III & 3 & 2048 \\
\hline & 21 & March & 1 & III & 3 & 2048 \\
\hline & 22 & March & 1 & III & 3 & 2048 \\
\hline & 23 & March & 2 & III & 3 & 512 \\
\hline & 24 & March & 1 & III & 3 & 2048 \\
\hline & 25 & March & 1 & III & 3 & 2048 \\
\hline & 26 & February & 1 & III & 3 & 2048 \\
\hline & 27 & February & 1 & III & 3 & 512 \\
\hline & 28 & March & 1 & III & 3 & 2048 \\
\hline & 29 & March & 1 & III & 3 & 1024 \\
\hline
\end{tabular}


Table 4) Clonality of MRSA strains isolated from hospital sewage in Tehran during 2015

\begin{tabular}{|c|c|c|c|c|c|c|}
\hline PhP Types & No & $\begin{array}{l}\text { Month of } \\
\text { Sampling }\end{array}$ & Prophage Pattern & SCCmec Type & ccr Type & $\operatorname{MIC}(\mu \mathrm{g} / \mathrm{mL})$ \\
\hline \multirow{25}{*}{ СТ2 } & 30 & March & 1 & III & 3 & 256 \\
\hline & 31 & March & 1 & III & 3 & 64 \\
\hline & 32 & March & 2 & III & 3 & 256 \\
\hline & 33 & February & 1 & III & 3 & 1024 \\
\hline & 34 & February & 1 & III & 3 & 1024 \\
\hline & 35 & February & 1 & III & 3 & 1024 \\
\hline & 36 & February & 1 & III & 3 & 512 \\
\hline & 37 & February & 1 & III & 3 & 2048 \\
\hline & 38 & February & 1 & III & 3 & 2048 \\
\hline & 39 & February & 1 & III & 3 & 512 \\
\hline & 40 & February & 1 & III & 3 & 2048 \\
\hline & 41 & March & 1 & III & 3 & 1024 \\
\hline & 42 & March & 1 & III & 3 & 1024 \\
\hline & 43 & March & 1 & III & 3 & 512 \\
\hline & 44 & March & 1 & III & 3 & 2048 \\
\hline & 45 & March & 1 & III & 3 & 1024 \\
\hline & 46 & February & 1 & III & 3 & 2048 \\
\hline & 47 & February & 1 & III & 3 & 2048 \\
\hline & 48 & February & 2 & III & 3 & 1024 \\
\hline & 49 & February & 1 & III & 3 & 2048 \\
\hline & 50 & March & 1 & III & 3 & 2048 \\
\hline & 51 & March & 1 & III & 3 & 2048 \\
\hline & 52 & March & 2 & III & 3 & 1024 \\
\hline & 53 & March & 1 & III & 3 & 512 \\
\hline & 54 & February & 1 & III & 3 & 64 \\
\hline \multirow{2}{*}{ СТ3 } & 55 & February & 1 & III & 3 & 256 \\
\hline & 56 & February & 2 & III & 3 & 2048 \\
\hline \multirow{6}{*}{ CT4 } & 57 & March & 1 & III & 3 & 1024 \\
\hline & 58 & March & 2 & III & 3 & 2048 \\
\hline & 59 & February & 1 & III & 3 & 2048 \\
\hline & 60 & February & 1 & III & 3 & 2048 \\
\hline & 61 & March & 1 & III & 3 & 2048 \\
\hline & 62 & March & 1 & III & 3 & 2048 \\
\hline
\end{tabular}


Table 4) Clonality of MRSA strains isolated from hospital sewage in Tehran during 2015

\begin{tabular}{lllllll}
\hline PhP Types & No & $\begin{array}{l}\text { Month of } \\
\text { Sampling }\end{array}$ & Prophage Pattern & SCCmec Type & ccr Type & MIC $(\mu \mathrm{g} / \mathrm{mL})$ \\
\hline \multirow{2}{*}{ CT5 } & 63 & March & 1 & III & 3 & 512 \\
\cline { 2 - 7 } & 64 & February & 2 & III & 3 & 64 \\
\hline \multirow{2}{*}{ CT6 } & 65 & March & 1 & III & 3 & 1024 \\
\cline { 2 - 7 } & 66 & March & 2 & III & 3 & 1024 \\
\hline \multirow{2}{*}{ CT7 } & 67 & March & 1 & III & 3 & 2048 \\
& 68 & February & 1 & III & 3 & 2048 \\
\hline \multirow{2}{*}{ CT8 } & 69 & March & 1 & III & 3 & 1024 \\
& 70 & March & 1 & III & 3 & 1024 \\
\hline ST1 & 71 & March & 1 & III & 3 & 1024 \\
\hline ST2 & 72 & March & 1 & III & 3 & 256 \\
\hline ST3 & 73 & February & 2 & III & 3 & 1024 \\
\hline ST4 & 74 & March & 2 & III & 3 & 1024 \\
\hline ST5 & 75 & February & 2 & III & 3 & 1024 \\
\hline ST6 & 76 & March & 1 & III & 3 & 2048 \\
\hline ST7 & 77 & March & 1 & III & 3 & 512 \\
\hline ST8 & 78 & February & 1 & III & 3 & 2048 \\
\hline
\end{tabular}

common among all 79 MRSA strains, while SGB prophage type was present only in $72 \%$ $(n=57)$ of the strains (Table 3). Moreover, two prophage patterns were also detected among all MRSA strains, and pattern 1 consisting of SGB, SGF, SGFa, and SGFb prophage types was the dominant one.

SCCmec and ccr typing: Among all mecA positive MRSA strains, only one SCCmec type and one ccr type were detected; all the strains harbored SCCmec type III and ccr type 3 and were classified as HA-MRSA strains (Table 4).

PhP typing: The results of PhP typing of 79 MRSA strains showed the presence of 16 PhP types among the strains, consisting of 8 common types (CTs) and 8 single types (STs); among which CT1 was the dominant type consisting of 29 strains (37\%) (Table 4 and Figure 3), followed by CT2, CT4, and CT8 containing of 25 (32\%), 6 (8\%), and 3 (4\%) MRSA strains, respectively. CTs 1, 2, 4, 5, and 7 were common among MRSA strains isolated in both sampling stages, while CT6 as well as CT8 and CT3 were only prevalent among the strains isolated in the second sampling stage in March and in the first sampling stage in February, respectively. On the other hand, different antibiotic resistance patterns and different prophage patterns were identified in a certain PhP type.

\section{Discussion}

In this study, the clonal dissemination of MRSA strains in a hospital sewage in Tehran was assessed using a combination of $\mathrm{PhP}$ typing, prophage typing, and SCCmec typing methods. In this research, during 2 sampling stages in 2015 from the outgoing wastewater of a referral hospital in Tehran, a total of 79 MRSA strains were isolated, indicating the high prevalence of MRSA strains in this hospital. As far as we know, there is no information about the prevalence of MRSA in hospital sewage in Iran, and this is probably the first report on MRSA strains in hospital 
Figure 3) Dendrogram showing the clonality of MRSA strains isolated from hospital sewage in Tehran during 2015

File: Torabi.ad No. of tests: 24 Method: U ID level: 0.975 Date: $3 / 31 / 2017$ Samples: 79 Co-phenetic corr: 0.909 Di: 0.764 (True Di: 0.761)

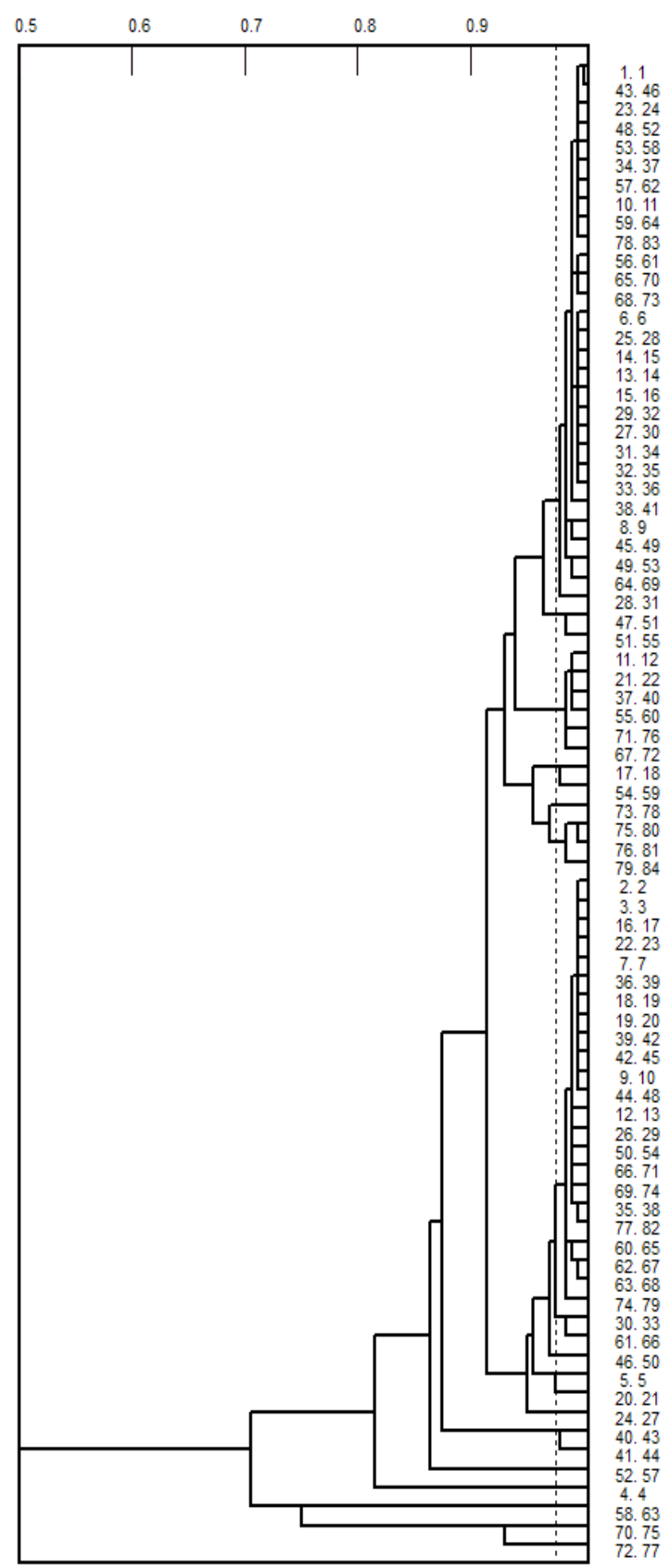

sewage in Iran; however, in different studies in Iran, the prevalence of MRSA strains in clinical, environmental, animal, and meat samples has been reported ${ }^{[2-3,5,17-21]}$; thus the presence of MRSA strains in hospital sewage was not surprising. Although in a study in Germany, no MRSA was detected among urban and hospital sewage ${ }^{[22]}$, in different studies in Iran ${ }^{[5,10]}$ and other countries ${ }^{[7-9,11]}$, the prevalence of MRSA strains in municipal sewage has been reported. The prevalence of MRSA strains in Tehran urban sewage has been reported to be $15.3 \%{ }^{[5,10]}$. Börjesson et al. (2010) in Sweden could isolate 189 MRSA strains from municipal wastewater [7]. Moreover, the presence of MRSA strains in hospital wastewater in Australia was also reported to be $27 \%(n=61)$ by Thompson et al. (2013) ${ }^{[11]}$. The differences between these studies results could be due in part to the differences in the prevalence of MRSA strains in different hospitals, the efficiency of the treatment process used, and the method employed for the isolation of MRSA strains. Furthermore, the prevalence of MRSA strains in some countries is very low (less than 1\%), compared to other countries with high prevalence of MRSA (e.g. Iran $\geq 20 \%$ ); therefore, it is not possible to accurately estimate the prevalence of MRSA strains in hospital and urban sewage in countries with high or low prevalence of MRSA strains.

Consistent with other studies in Iran, none of the MRSA strains were resistant to vancomycin, quinupristin-dalfopristin, linezolid, and chloramphenicol [2-5, 10, 12, 14, 17, 19-20, 23-24], which could be due to the low or no consumption of these antibiotics for the treatment of staphylococcal infections in Iran. Moreover, a high rate of resistance to ciprofloxacin, amikacin, tobramycin, erythromycin, amikacin, clindamycin, and tetracycline was observed among MRSA strains, which is consistent with other reports on clinical, environmental, and meat samples in Iran [2-5, 10, 12, 14, 17, 19-20, 23-24].

In the present study, all MRSA strains were resistant to cefoxitin and also were positive for mecA gene. Several studies have already reported similar results among MRSA strains ${ }^{[3,5,20,25]}$. Although some MRSA strains are negative for mecA gene and instead harbor mecC gene, but since there is very 
low or no report on $m e c C$ gene in Iran, it could be concluded that detection of mecA gene could be a rapid and specific method for detecting MRSA strains in this country. All MRSA strains harbored SCCmec type III and $\mathrm{crr}$ type 3 and were classified as HAMRSA strains. This finding is similar to the finding of another study on MRSA strains of poultry origin, in which only SCCmec type III was detected ${ }^{[17]}$. In other studies, different SCCmec types (III, IV and V) have been reported, and type III has been reported as the dominant one ${ }^{[2-3,5,19-20]}$. Moreover, the present study result is different from that of another research in the United States, in which MRSA strains in STPs harbored SCCmec types II and IV ${ }^{[9]}$. It seems that the sewage treatment process in the hospital under study could eliminate MRSA strains with SCCmec types IV, V, and VII (CA-MRSA), while strains with SCCmec type III (probably other SCCmec types) could survive during the treatment process.

In this study, SGB, SGF, SGFa, and SGFb prophage types as well as two prophage patterns were detected among MRSA strains, and all the strains were negative for SGA, SGD, and SGL prophage types. In different studies in Iran, SGA and SGL prophage types have also been identified among CA-MRSA strains, and diverse prophage patterns have also been reported among MRSA strains of clinical, meat, and sewage origins $[2-3,5,14,20$, 26-27]. These differences in the prevalence of prophage types among MRSA strains in different samples in Iran could be due to the dissemination of different strains in various cities and hospitals worldwide.

High-resolution $\mathrm{PhP}$ typing method is a powerful and specific method used to type $S$. aureus strains, and the usefulness and efficiency of PhP typing for MRSA strains have already been reported [3, 5, 10, 12, 20]. In this study, diverse PhP types consisting of 8 CTs and 8 STs were reported. More diverse
PhP types (33 and $21 \mathrm{PhP}$ types) have already been reported in strains isolated from clinical and urban sewage samples [3, 5, 12]. CT1 was the dominant PhP type in this study, followed by CT2, CT4, and CT8. Compared to our previous studies $[3,5,10,12$, $17,19,20]$, it was found that certain clonal $\mathrm{PhP}$ types are disseminating and circulating in different regions in Tehran. Moreover, the presence of MRSA strains with different antibiotic resistance and prophage patterns in a certain PhP type in this study indicated independent evolution of such clones in the community. On the other hand, the presence of some strains, isolated during two sampling stages, in CT7 with similar prophage pattern and antibiotic resistance patterns indicated the presence and persistence of this clone type in this hospital over two months of sampling.

\section{Conclusions}

The results of this study indicated the presence and persistence of different clonal groups of MDR MRSA strains in the outgoing sewage of the studied hospital in Tehran. These clone types, which harbor SCCmec type III as well as SGF prophage type and its two subtypes (SGFa and SGFb), have a high potential to produce a variety of virulence factors, such as enterotoxins (A, G, K, P and $\mathrm{Q})$, leukocidin, staphylokinase, and $\beta$-lysine, and could enter the environment or sewagetreatment systems and survive there for a long time. These strains could also survive during the sewage treatment process, as the sewage treatment process has already been shown to be unable to remove all MRSA strains, and some MRSA strains (with SCCmec type III) could survive during the sewage treatment process and enter the environment ${ }^{[5]}$. The high prevalence of such strains in hospitals and consequently in the community could be considered as a potential threat to public health. 
Acknowledgment: Not applicable.

Ethical Permission: Not applicable.

Conflict of Interest: The authors declare that there is no conflict of interest with the organization that sponsored this research and publications arising from this research. Authors contributions: Conceptualization: FR; Data curation and formal analysis: MT and FR; Investigation: MT and FR; Methodology and project administration: FR; Supervision: FR; Validation: FR; Writing of original draft: MT; Writing, reviewing, and editing: FR.

Fundings: The results presented in this paper were part of Mina Torabi's MSc thesis supported by a research budget from University of Isfahan.

Consent to participate: Consent was obtained from the Hospital Infection Control Committee.

\section{References}

1. Hanssen AM, Ericson Sollid JU. SCCmec in staphylococci: Genes on the move. FEMS Immunol Med Microbiol. 2006;46(1):820.

2. Rahimi F, Katouli M, Karimi S. Biofilm production among methicillin resistant Staphylococcus aureus strains isolated from catheterized patients with urinary tract infection. Microb Pathog. 2016;98:69-76.

3. Rahimi F, Katouli M, Pourshafie MR. Characteristics of hospital- and community-acquired meticillin-resistant Staphylococcus aureus in Tehran, Iran. J Med Microbiol. 2014;63(6):796-804.

4. Fatholahzadeh B, Emaneini M, Gilbert G, Udo E, Aligholi M, Modarressi MH, et al. Staphylococcal cassette chromosome mec (SCCmec) analysis and antimicrobial susceptibility patterns of methicillinresistant Staphylococcus aureus (MRSA) isolates in Tehran, Iran. Microb Drug Resistance. 2008;14(3):217-20.
5. Rahimi F, Katouli M, Pourshafie MR. Characterization of methicillin-resistant Staphylococcus aureus strains in sewage treatment plants in Tehran, Iran. J Water Health. 2021;19(2):216-28.

6. Börjesson $S$, Dienues 0 , Jarnheimer P-Å, Olsen B, Matussek A, Lindgren P-E. Quantification of genes encoding resistance to aminoglycosides, $\beta$-lactams, and tetracyclines in wastewater environments by real-time PCR. Int J Environ Health Res. 2009;19(3):219-30.

7. Börjesson $\mathrm{S}$, Matussek $\mathrm{A}$, Melin $\mathrm{S}$, Löfgren S, Lindgren P-E. Methicillinresistant Staphylococcus aureus (MRSA) in municipal wastewater: An uncharted threat? J Appl Microbiol. 2010;108(4):1244-51.

8. Börjesson S, Melin S, Matussek A, Lindgren P-E. A seasonal study of the mecA gene and Staphylococcus aureus including methicillin-resistant $\mathrm{S}$. aureus in a municipal wastewater treatment plant. Water Res. 2009;43(4):925-32.

9. Goldstein RER, Micallef SA, Gibbs SG, Davis JA, He X, George A, et al. Methicillin-resistant Staphylococcus aureus (MRSA) detected at four US wastewater treatment plants. Environ Health Perspect. 2012;120(11):1551-8.

10. Rahimi F, Bouzari M. Biochemical fingerprinting of methicillin-resistant Staphylococcus aureus isolated from sewage and hospital in Iran. Jundishapur J Microbiol. 2015;8(7):e19760.

11. Thompson J, Gündoğdu A, Stratton $\mathrm{H}$, Katouli M. Antibiotic resistant Staphylococcus aureus in hospital wastewater and sewage treatment plants with special reference to methicillinresistant Staphylococcus aureus (MRSA). J Appl Microbiol. 2013;114(1):44-54. 12. Rahimi F, Shokoohizadeh L. Characterization of methicillin resistant Staphylococcus aureus strains among 
inpatients and outpatients in a referral hospital in Tehran, Iran. Microb Pathog. 2016;97:89-93.

13. Pantůček R, Doškař J, Růžičková $V$, Kašpárek $\mathrm{P}$, Oráčová $\mathrm{E}$, Kvardová $\mathrm{V}$, et al. Identification of bacteriophage types and their carriage in Staphylococcus aureus. Arch Virol. 2004;149(9):1689-703.

14. Rahimi F, Bouzari M, Katouli M, Pourshafie MR. Prophage and antibiotic resistance profiles of methicillin-resistant Staphylococcus aureus strains in Iran. Arch Virol. 2012;157(9):1807-11.

15. Clinical and Laboratory Standard Institute C. Performance standards for antimicrobial susceptibility testing, $26^{\text {th }}$ informational supplement. Wayne, Pa: Clinical and Laboratory Standard Institute; 2016.

16. Zhang K, McClure J-A, Elsayed S, Louie T, Conly JM. Novel multiplex PCR assay for characterization and concomitant subtyping of staphylococcal cassette chromosomemectypes ItoVin methicillinresistant Staphylococcus aureus. J Clin Microbiol. 2005;43(10):5026-33.

17. Rahimi F, Karimi S. Characteristics of methicillin resistant Staphylococcus aureusstrainsisolated from poultryiniran. Arch Clin Infect Dis. 2015;10(4):e30885.

18. Rahimi F, Karimi S. Isolation of methicillinresistant Staphylococcus aureus strains producing enterotoxins $\mathrm{A}, \mathrm{K}$, and $\mathrm{Q}$ from chicken meat in Isfahan, Iran, 2014. Arch Clin Infect Dis. 2016;11(4):e35601.

19. Rahimi F, Qasemi A. Epidemiological link between methicillin-resistant Staphylococcus aureus strains isolated from 2 different cities in Iran. Infect Dis Clin Pract. 2019;27(3):163-9.

20. Rahimi F, Shafiei R. Characteristics of enterotoxin-producing methicillinresistant Staphylococcus aureus strains isolated from meat in Tehran, Iran. J
Consum Prot Food Saf. 2019;14(4):38998.

21. Rahimi F, Shokoohizadeh L. Characterization of virulence factors and prophage profiles of methicillin-resistant Staphylococcus aureus strains isolated from a referral hospital in Tehran, Iran. Arch Clin Infect Dis. 2018;13(5):e59385.

22. Schwartz T, Kohnen W, Jansen B, Obst U. Detection of antibiotic-resistant bacteria and their resistance genes in wastewater, surface water, and drinking water biofilms. FEMS Microbiol Ecol. 2003;43(3):325-35.

23. Goudarzi M, Goudarzi H, Figueiredo AMS, Udo EE, Fazeli M, Asadzadeh M, et al. Molecular characterization of methicillin resistant Staphylococcus aureus strains isolated from intensive care units in Iran: ST22-SCCmec IV/t790 emerges as the major clone. PloS One. 2016;11(5):e0155529.

24. Rahimi F, Bouzari M, Katouli M, Pourshafie MR. Antibiotic resistance pattern of methicillin resistant and methicillin sensitive Staphylococcus aureus isolates in Tehran, Iran. Jundishapur J Microbiol. 2013;6(2):144-9.

25. Rahimi F, Bouzari M, Maleki Z, Rahimi F. Antibiotic susceptibility pattern among Staphylococcus spp. with emphasis on detection of mecA gene in methicillin resistant Staphylococcus aureus isolates. Iran J Clin Infect Dis. 2009;4(3):143-50.

26. Rahimi F, Bouzari M, Katouli M, Pourshafie M. Prophage typing of methicillin resistant Staphylococcus aureus isolated from a tertiary care hospital in Tehran, Iran. Jundishapur J Microbiol. 2013;6(1):80-5.

27. Rahimi F, Karimi S. Characteristics of virulence factors in methicillin-resistant Staphylococcus aureus strains isolated from a referral hospital in Tehran, Iran. Arch Clin Infect Dis. 2016;11(1):e33220. 